\title{
Psychopathological Organizations and Attachment Styles in Patients with Fear of Flying: A Case Study
}

\author{
Guido Veronese ${ }^{1, *}$, Rossella Procaccia ${ }^{2}$, Diego Romaioli ${ }^{3}$, Gianpiero Barola ${ }^{4}$ and Marco Castiglioni ${ }^{1}$ \\ ${ }^{1}$ Department of Human Sciences “R. Massa”, University of Milano-Bicocca, Piazza dell' Ateneo Nuovo 1, 20126, Mi- \\ lano, Italy \\ ${ }^{2}$ Department of Psychology, Università degli studi eCampus, via Isimbardi 10, 22060, Novedrate, Italy \\ ${ }^{3}$ Department of Philosophy, University of Verona, via San Francesco, 22, 37129, Verona, Italy \\ ${ }^{4}$ Department of Statistic, Piazza dell'Ateneo Nuovo 1, 20126, Milano, Italy
}

\begin{abstract}
Objectives: The scope of the study is to identify the leading "organization of meaning" in patients affected by aviophobia and the related attachment style. Specifically we hypothesized that participants with fear of flying would predominantly display a phobic organization of meaning, associated with an anxious-ambivalent attachment style.

Methods: 150 adults, divided between an experimental group (FOF) and a control group (CON), completed three research instruments: two self-report questionnaires assessing attachment style (AAQ and ASQ) and the self-characterization, a qualitative constructivist tool.

Results: The insecure attachment style prevailed in aviophobics rather than control group. Socio-economic and gender differences were found. The vocabulary used by the group with flying phobia featured a system of meaning referring to "freedom" family semantics.

Conclusions: Attachment style appears to be a necessary but insufficient condition for predicting fear of flying. A greater role in the disorder is played by the organization of patients' personality, as argued by socio-constructionist and constructivist authors. Implication for clinical work and psychotherapy are discussed.
\end{abstract}

Keywords: Fear of Flying, attachment style, system of meaning, constructivism.

\section{INTRODUCTION}

Fear of flying (FOF) or aviophobia is a well-known mental disorder that affects almost $25 \%$ of air travelers or 25 million individuals $[1,2]$. FOF sufferers are impeded in their ability to engage in air travel due to varying degrees of anxiety or stress. Around $20 \%$ of these passengers rely on alcohol or sedatives to help them deal with the anxiety and other symptoms caused by fear of flying [3, 4]. The frequency of diagnostic factors underlying fear of flying is broadly bimodal in distribution. About half of patients with fear of flying symptoms meet the criteria for specific phobias, displaying a deep-seated fear of something negative happening to the aircraft (e.g., falling apart, crashing, etc..). The other half of the fear of flying population suffer from agoraphobia, with or without panic disorder, who fear having a panic attack in a context from which there is no escape route [5]. Individuals affected by fear of flying may experience a range of physiological and psychological symptoms. These

*Address correspondence to this author at the Department of Human Sciences "R. Massa", University of Milano-Bicocca, Piazza dell' Ateneo Nuovo 1, 20126, Milano, Italy; Tel: +39(0)264484800;

Fax:+39 (0)264484863; E-mail: guido.veronese@unimib.it symptoms may occur during the flight or even weeks or months beforehand in anticipation of flying. Physical symptoms may include rapid heart-beat, tightness or pain in the chest, butterflies in the stomach, nausea or vomiting, and cold, weak or trembling hands or feet. Psychological symptoms may include difficulty in concentrating, worry, dread or fear that something terrible is going to happen, or the feeling of being trapped or powerless [4]. Aviophobia involves a marked and persistent fear that is excessive and unreasonable, and is cued by anticipation of, or actual, flying on an airplane. Exposure to flying cues, such as booking a flight, sitting on an airplane, or the sounds and sight of taking off, provoke an immediate anxiety response, which may also yield a panic attack. Although people with aviophobia recognize that their fear is excessive and unreasonable, they either avoid flying, or endure it with great distress [6].

According to the DSM IV [7, 8], fear of flying is a specific phobia. Clinical diagnosis of the disorder requires the following criteria to be met:

1. Exposure to the phobic stimulus invariably produces an almost immediate anxiety response. 
2. The response may take the form of a situationally bound or situationally predisposed panic attack — although the fear response is recognized by the sufferer (unless they are children) as unreasonable.

3. Generally the stimulus is avoided.

4. The diagnosis is appropriate only if the avoidance, fear, or anxious anticipation of encountering the phobic stimulus interferes significantly with the person's daily routine, occupational functioning, or social life, or if the person is markedly distressed about having the phobia.

5. There is not a more fitting explanation for the accompanying anxiety, panic attacks, or phobic avoidance, such as OCD, PTSD, separation anxiety disorder or social phobia [9].

\subsection{Theoretical Background}

A key distinctive trait of constructivist perspectives in psychotherapy is a specific interest in processes of meaning construction [10,11]. Guidano [12] defined psychopathology as a "science of meaning", developing the notion that "personal meaning organization" guides the process of meaningmaking underpinning selfhood development and promotes coherence and stability in personal identity. He identified four pathological personal meaning organizations (phobic, depressive, obsessive-compulsive and eating disorderrelated), each associated with a peculiar set of meanings and specific ways of constructing them [13]. Some of the ideas in Guidano's theory have been reinterpreted in a fully original fashion by Ugazio [14] who has developed the theory of "Family Semantic Polarities" (FSP). Her theory falls within the family therapy tradition, but - differently from family therapy pioneers $[15,16$,$] - Ugazio focuses on semantics$ rather than pragmatics. In this regard, her thinking is close to that of a number of constructivist authors, including Kelly [17], Guidano [12, 13], Neimeyer and Mahoney [10], Procter [18-21], although again with elements of originality. Following a systemic-constructionist approach, FSP theory relates to the joint construction of meaning within the family. According to Ugazio, the prevalence in family conversation of specific semantics is a necessary condition for a member to develop a psychological disorder, but alone is not a sufficient condition given that the outcome also depends on the reciprocal positioning of family members in relation to the critical semantics [22]. Taking up a certain position within the relational and semantic context of one's family may cause an individual family member to experience a paradoxical dilemma or "strange loop", assumed to be amongst the causes of the psychological disorder [23].

The research presented here is the extension of an earlier pilot study carried out by the authors in 2008 [24]. Following a systemic-constructionist theoretical perspective $[25,26]$ and Ugazio's theory [14], we view phobias and anxiety disorders as developing within family learning contexts in which the conversation is organized around salient themes (semantic polarities) related to freedom/dependence and to the emotions fear/courage [27, 28].

The principal semantic polarities linked to a phobic organization of personality may be summarized as follows [27].
Strong

Enterprising

Alone

Distancing oneself

Being Closed

Freeing oneself from ties

Calm

Guidano $[12,13]$ refers to a phobic type of personality organization, in which the subject perceives fear not as a psychological manifestation but as a physical sensation: the phobic patient tends to equate subjective experience with sensory experience, to the extent that all emotional states are perceived in terms of neuro-vegetative responses (increased heart rate, breathing difficulties etc.), thus making emotions undistinguishable from somatic sensations and their related medical conditions. The attachment style underlying this type of semantic meaning is anxious-ambivalent. This pattern of attachment is a direct consequence of hyperprotective parenting inhibiting the child's normal exploration of its environment at an early stage of development [13, 29-31].

The aim of the present study was to identify the leading "organization of meaning" in patients affected by aviophobia and the related attachment style [12-14]. Specifically, in line with our own previous pilot research [24], we hypothesized that participants with fear of flying would predominantly display a phobic organization of meaning $[14,28]$, associated with an anxious-ambivalent attachment style [13, 29$31]$.

\section{METHOD}

The study was carried out with travelers affected by flying phobia, attending a cognitive-behavioral therapeutic program ("Wanting to fly") organized by Alitalia to help individuals address difficulties related to fear of flying, and with a control group of frequent flyers. The data was collected following the ethical guidelines and confidentiality criteria of the Research Ethics Committee of the Italian Ministry of Education and the code of ethics of the Italian Order of Psychologists. All participants in both "flying phobia" and "control" groups provided informed consent before the research was initiated.

\subsection{Participants}

Participants in the study were 150 adults evenly distributed by age and gender and predominantly from a mediumhigh socio-economic and educational background. They were divided between an experimental group (FOF) and a control group (CON) (see Table 1).

The "flying phobia" group (FOF) was composed of 32 men (average age $=38.56 ; S D=11.45$; range $=19-46$ ) and 43 women (average age $=38.16 ; S D=10.19$; range $=22$ 60 ). At the time of the research, they were all attending a cognitive-behavioral therapeutic program provided by the Alitalia group with the aim of reducing fear and avoidance in individuals affected by flying phobia. The control group (CON) consisted of 75 Alitalia employees who flew fre- 
Table 1. Sample Distribution in Aviophobics'(FOF) and Travelers' Groups

\begin{tabular}{|c|c|c|c|c|}
\hline \multirow{2}{*}{ Sex } & \multicolumn{2}{|c|}{ Aviophobic (FOF) } & \multicolumn{2}{c|}{ Control (CON) } \\
\cline { 2 - 5 } & N. & Age & 30 & Age \\
\hline \hline Male & 32 & $38.56(\mathrm{sd} 11.45)$ & 45 & $30.93(\mathrm{sd} 8.81)$ \\
\hline Female & 43 & $38.16(\mathrm{sd} 10.19)$ & 75 & 150 \\
\hline Total & 75 & & $\mathrm{sd} 11.45)$ \\
\hline
\end{tabular}

quently as part of their work and who had volunteered to take part in the research (30 men, average age $=40.93$; $\mathrm{SD}=$ 8.81 ; range $=26-58$; and 45 women: average age $=38.56$; $\mathrm{SD}=11.45 ;$ )

In order to explore the effect of age on the experimental variables the sample was divided into three age groups: 1830 years $(24.7 \%) ; 31-40(40.2 \%)$; over 40 (34.7\%).

\subsection{Instruments and Procedure}

Participants completed three research instruments: two self-report questionnaires assessing attachment style (AAQ and ASQ) and a self-characterization [17].

The Adult Attachment Questionnaire (AAQ) [32]. This questionnaire consists of three brief untitled descriptions of attachment patterns in close relationships. The participants are asked to choose the description most closely corresponding to their own habitual way of relating to others. Each of the three descriptions represents a specific attachment style : a) secure style (describes situations involving confidence in others, friendship and other positive aspects of interpersonal relationships); b) avoidant style (describes interpersonal situations involving fear of close relationships and "ties"); c) anxious ambivalent style (describes situations involving the fear of not being loved and the tendency to seek overinvolvement in relationships).

The Attachment Style Questionnaire (ASQ) [33]. This is a self-report questionnaire evaluating individual differences in adult attachment style [34]. The questionnaire is made up of 40 items to be rated on a 6-point Likert scale. The items are subdivided into five subscales, relating to secure, avoidant and anxious attachment styles. The subscales cover:

a. Confidence (10 items), reflecting a secure attachment style;

b. Discomfort with Closeness (10 items), corresponding to an avoidant attachment style;

c. Need for Approval (7 items), related to an anxiousambivalent attachment style;

d. Preoccupation with Relationships (7 items), measuring anxiety and dependence in relationships, characteristic of anxious-ambivalent attachment [32];

e. Relationships as Secondary (8 items), related to avoidant attachment and to the dismissive attachment style described by Bartholomew and Horowitz [35].

Each item is rated on a 6-point scale, ranging from 1 (totally disagree) to 6 (totally agree). To avoid response bias, the items are listed in random order and three items are reverse-scored. The ASQ showed adequate reliability and construct validity in university and secondary student samples [36].

Self-characterization [17]. This is a qualitative and constructivist instrument par excellence. Each individual is asked to write a brief but complete sketch of him/herself in the third person, from the perspective of a close and favorably disposed friend. It is a writing task used by constructivist therapists as a form of assessment and based on Kelly's principle "if you do not know what is wrong with someone, ask them, they may tell you" [37, p. 241]. The instructions are as follows: "I want you to write a character sketch of (for example) Harry Brown just as if he were the principal character in a play. Write it as it might be written by a friend who knew him intimately and very sympathetically, perhaps better than anyone really could know him. Be sure to write it in the third person. For example, start out by saying, "Harry Brown is . .." [37, p. 242]. Use of the self-characterization tool as both a means of assessment and part of the therapeutic process, has been described by personal construct therapists [38].

\subsection{Data Analysis}

The data from the self-report questionnaires was analyzed in two steps using SPSS 18 software. First the chisquare test was applied to establish whether there were significant differences between the experimental and control groups in terms of attachment style as recorded by the AAQ. Then a t-test and a one-way analysis of variance (ANOVA) was carried out to check for differences between the two groups on the subscales of the ASQ. Pearson correlation analysis was conducted for both FOF and CON groups.

The self-characterizations were analyzed using SPAD software (SpadVersion: MN: 6.0.1, Paris, France) for quantiqualitative textual analysis .

Specifically content analysis was conducted in order to identify both semantic meanings denoting phobic cognitive organization and other potentially significant dimensions of meaning for each group. To this end, the Vospec (specific vocabularies) procedure from the software Spad was applied to the self-characterization texts. The texts were treated beforehand with a view to facilitating comprehension of how participants used particular terms, or words. Guideline criteria were applied in order to construct equivalences, grouping words together on the basis of semantic meaning. This involved keeping homographs separate and grouping synonyms together. Homographs are words which are the same 
but have different meanings; synonyms are different words sharing the same meaning. In addition, words considered irrelevant to the analysis were eliminated following two main criteria:

a. words with no significance in relation to the research objectives were eliminated (e.g. conjunctions and prepositions such as "but", "and", "with" etc.);

b. low frequency words were eliminated (three occurrences or less).

The Vospec procedure yielded specificity measures indicating to what extent certain words were characteristic of one group compared to the other. The analysis generated frequency tables, such as those reported in the Results section below, showing the characteristic words of the flying phobia group compared to the control group (the terms are listed in order of significance); The calculation performed was the value-test measuring the difference between the percentage frequency of a graphic form in a given class and total percentage frequency (the level of statistical significance was fixed at $\mathrm{p}<0.05$; in some cases statistically non-significant words have been reported on account of their pertinence in terms of meaning, especially when these words were exclusive to one group).

Finally, the two types of data analysis were combined following a parallel analysis procedure [39]. The characteristic vocabulary patterns identified by Spad are examined in conjunction with the quantitative results in the Discussion section below.

\section{RESULTS}

Table 2 summarizes the descriptive statistics for the main ASQ variables under study: Confidence ; $(\alpha=.70)$, Discom- fort with Closeness $(\alpha=.70)$, Need for Approval $(\alpha=.74)$, Preoccupation with Relationships $(\alpha=.72)$, and Relationships as Secondary $(\alpha=.80)$.

In Table 3 we report the distribution of the sample with regard to the three main attachment styles recorded by AAQ.

The secure attachment style prevailed in both aviophobics $(\mathrm{n}=43)$ and control group $(\mathrm{n}=58)$. In the frequent traveler $(\mathrm{CON})$ group, 14 people displayed an avoidant, and only three an anxious-ambivalent, attachment style, while in the phobic group (FOF), 26 displayed an avoidant and nine an anxious-ambivalent style.

Finally, socio-economic status was similar and balanced in the two groups: $16 \%$ were unemployed, $46 \%$ employees, $22.7 \%$ freelance professionals and $15 \%$ senior managers and business owners.

The correlations between ASQ, age, professional status and gender are reported in Table 4. Age and gender were positively correlated with occupational status. Older men tended to hold more prestigious professional positions. Older males also displayed greater confidence and avoidance, while older participants in general reported higher levels of confidence, discomfort with closeness and need for approval but a lesser tendency to view relationships as secondary. Confidence was negatively correlated with all the other ASQ subscales: discomfort with closeness, need for approval, relationships as secondary and preoccupation with relationships, which were positively correlated with one another.

A two-sample t-test was also carried out for the two independent groups to check for differences in attachment style between CON and FOF participants. Statistically significant differences were found between the two groups for all the dimensions of attachment: specifically, the control

Table 2. Descriptive Data Regarding the Scores of All Participants on the Subscales of the Attachment Style Questionnaire

\begin{tabular}{|c|c|c|c|c|c|c|}
\hline Variables & Mean & sd & Range & Percentile 25 & Percentile 50 & Percentile 75 \\
\hline Confidence & 4.12 & .73 & 3.63 & 3.75 & 4.18 & 4.62 \\
\hline Discomfort with Closeness & 3.51 & .72 & 3.80 & 3.00 & 3.60 & 4.00 \\
\hline Relationships as Secondary & 2.18 & .87 & 4.00 & 1.57 & 2.28 & 2.71 \\
\hline Preoccupation with Relationships & 3.39 & .86 & 4.63 & 2.87 & 3.37 & 4.00 \\
\hline
\end{tabular}

Table 3. Distribution of Attachment Styles (Secure, Avoidant, Anxious-ambivalent) Amongst All Participants

\begin{tabular}{|c|c|c|c|}
\hline Attachment Style & F & Percent. & Cumulative Percent. \\
\hline \hline Secure & 101 & 67.3 & 67.3 \\
\hline Avoidant & 40 & 26.7 & 94.0 \\
\hline Anxious/amb. & 9 & 6.0 & 100.0 \\
\hline Total & 150 & 100.0 & \\
\hline
\end{tabular}


Table 4. Pearson Correlations between Demographic Variables and ASQ Subscales

\begin{tabular}{|c|c|c|c|c|c|c|c|c|}
\hline Variables & 1 & 2 & 3 & 4 & 5 & 6 & 7 & 8 \\
\hline Gender & 1 & $-.363^{* *}$ & $-.138^{*}$ & -.033 & $-.146^{*}$ & $-.252^{* *}$ & .062 & 0.044 \\
\hline Occupation & & 1 & $0.135^{*}$ & 0.078 & 0.051 & 0.110 & 0.018 & -0.044 \\
\hline Age Group & & & 1 & $.025^{*}$ & $.016^{*}$ & $-.006^{*}$ & $.015^{*}$ & .017 \\
\hline Confidence & & & & 1 & $-.357^{* *}$ & $-.268^{* *}$ & $-.486^{* *}$ & $-.365 * *$ \\
\hline Discomfort with closeness & & & & & 1 & $.228 * *$ & $.212 * *$ & $.227 * *$ \\
\hline Relationships as secondary & & & & & & 1 & $.437^{* *}$ & $.266^{* *}$ \\
\hline Need for Approval & & & & & & & 1 & $.636^{* *}$ \\
\hline Preoccupation with relationships & & & & & & & & 1 \\
\hline
\end{tabular}

participants displayed greater Confidence than the flying phobia group $(t=-2,76 ; d f=135,7 ; p=0$. 006), whereas the latter obtained higher scores for Discomfort with Closeness $(t=-1,99 ; d f=145,58 ; \mathrm{p}=0.048)$, Relationships as Secondary $(t=-2,24 ; d f=138,15 ; \mathrm{p}=0.027)$, Need for Approval $(t=-2,28$; $d f=144,55 ; \mathrm{p}=0.024)$, and Preoccupation with Relationships $(t=-3,71 ; d f=135,7 ; \mathrm{p}=0.006)$.

A one-way ANOVA and Bonferroni post hoc test were carried out for each group, with age, socio-economic status, gender and attachment style as independent variables. In the FOF group, the younger adults showed greater need for approval than the middle aged participants $\left(\mathrm{F}_{2,72}=2.801 ; \mathrm{p}<\right.$ 0.1- Bonferroni post-hoc test between 31-40- and 18-30, $\mathrm{p}<0.1)$. Regarding socio-economic status, aviophobic participants who were jobless or employed by others reported a greater tendency to view relationships as secondary compared to individuals of higher occupational status. $\left(\mathrm{F}_{3,71}=3.875 ; \mathrm{p}<.05-\right.$ Bonferroni post hoc test jobless - business owners, $\mathrm{p}<0.05$; employees - business owners, $\mathrm{p}<.05$ ). Regarding attachment styles in the FOF group, there were significant differences between Secure and Avoidant styles in relation to Confidence $\left(\mathrm{F}_{2,72}=17.841 ; \mathrm{p}<.01\right.$ Bonferroni post hoc test, $\mathrm{p}<, 01)$; between Secure and Avoidant as well as between Avoidant and Ambivalent in relation to Discomfort with Closeness $\left(\mathrm{F}_{2,72}=10.89 ; \mathrm{p}<.01\right.$; Bonferroni post hoc test $p<.01$ and $p<.05$, respectively); and between Secure and Avoidant as well as between Secure and Ambivalent regarding Need for Approval $\left(\mathrm{F}_{2,72}=8.917 ; \mathrm{p}<.01\right.$; Bonferroni test $\mathrm{p}<.01 ; \mathrm{p}<.1)$. Finally, regarding Preoccupation with Relationships, there was a statistically significant difference between Secure and Avoidant styles $\left(\mathrm{F}_{2,72}=3.365\right.$; $\mathrm{p}<.05$; Bonferroni test $\mathrm{p}<.1$ ).

In the control group, levels of Confidence varied significantly as a function of socio-economic status. Specifically, control participants with higher socio-economic status were more confident than lower-level employees $\left(\mathrm{F}_{3,71}=2.514\right.$; $\mathrm{p}<, 1$; Bonferroni test $\mathrm{p}<.1$ ). Discomfort with Closeness and Need for Approval also varied significantly as a function of Secure vs. Avoidant attachment $\left(\mathrm{F}_{2,72}=4.995\right.$; $\mathrm{p}<, 01$; Bonferroni test $\mathrm{p}<.01$ and $\mathrm{F}_{2,72}=3.948 ; \mathrm{p}<.05$ Bonferroni test $\mathrm{p}<.1)$.
The quantitative data just reported do not lend themselves to straightforward interpretation. In the first place, both control and phobic groups contained individuals with non-secure attachment styles. However, the aviophobic group seemed to display a greater trend towards non-secure styles than the control group. Socio-economic status and age appeared to act as protective factors, but we do not have sufficient data to generalize such a conclusion. Given that both avoidant and anxious styles were present in the aviophobic group, we cannot conclude that either of these two styles is prevalent in fear of flying.

Qualitative data is of more assistance in building up a detailed and specific picture of the disorder. Below we report the differences found between fear of flying and control groups by applying Vospec analysis of the selfcharacterizations.

In Tables $\mathbf{5}$ and $\mathbf{6}$ we present the most dominant words in the self-construals of the FOF and CON groups, respectively.

In line with our hypotheses, the vocabulary used by the group with flying phobia featured multiple words and expressions more or less explicitly referring to "freedom" family semantics.

More specifically, the aviophobic "definition of self" was dominated by the bipolar semantic dimensions of "Unpredictable-Reliable" and "In the fray-Protected". Participants with flying phobia therefore tended to describe themselves as reliable, attributing a range of meanings to this construct. For example, some respondents emphasized that they saw themselves as "rational", (that is to say, analytical, realistic, consistent, logical, calculating, controlled..), 'precise' (exact, rigorous, punctual..) and" "careful".

Such a positioning of the self often goes hand in hand with a description of others as "Unpredictable", to the extent that the construct most commonly used by FOF participants to refer to their relationships with others was "lack of trust".

This low level of trust in others, perceived as unpredictable, combined with a self-perception of stability and reliability, contributes to an attitude of "intransigence" on the part of aviophobics, that is to say, a tendency to define the self as intolerant or little inclined to forgive others for wrongs suffered. Close analysis of the self-characterizations 
Table 5. Specific Vocabulary (Vospec) Characterizing Aviophobics

\begin{tabular}{|c|c|c|c|}
\hline Characteristic Words or Segments & Internal Frequency & Total Frequency & Probability ${ }^{\mathrm{a}}$ \\
\hline closing up & 14 & 16 & 0.002 \\
\hline cutting oneself off & 18 & 24 & 0.013 \\
\hline shy & 8 & 9 & 0.022 \\
\hline knowing oneself to be unpopular & 4 & 4 & $0.067^{*}$ \\
\hline grateful & 4 & 4 & 0.067 \\
\hline presumptuous & 6 & 7 & $0.068^{*}$ \\
\hline precise & 7 & 9 & 0.098 \\
\hline intransigent & 8 & 11 & 0.124 \\
\hline pessimistic & 6 & 8 & $0.155^{*}$ \\
\hline careful & 6 & 8 & 0.155 \\
\hline seeking help & 7 & 10 & 0.185 \\
\hline jealous & 4 & 5 & 0.198 \\
\hline goal-driven & 4 & 5 & $0.198^{*}$ \\
\hline unhappy & 4 & 5 & $0.198^{*}$ \\
\hline
\end{tabular}

${ }^{a}$ the probability values refer to statistically significant differences with respect to the CON group;

$* \mathrm{p}<0.05$

Table 6. Specific Vocabulary (Vospec) Characterizing the Control Group

\begin{tabular}{|c|c|c|c|}
\hline Characteristic Words or Segments & Internal Frequency & Total Frequency $^{\text {Probability }^{\mathbf{a}}}$ \\
\hline \hline brave & 10 & 12 & 0.016 \\
\hline intelligent & 17 & 24 & 0.025 \\
\hline likeable & 21 & 31 & 0.027 \\
\hline can be got around & 5 & 5 & 0.028 \\
\hline positive & 13 & 18 & 0.040 \\
\hline
\end{tabular}

athe probability values refer to statistically significant differences with respect to the FOF group;

reveals a tendency on the part of flying phobia patients to be selective and demanding towards others, preferring to establish close relationships with a narrow circle of people, judged for one reason or another to be reliable compared to an external world perceived as generally threatening. Constructs such as "jealous" or "grateful" denote emotions that would be congruous with such a family pattern of construing interpersonal relations.
This way of organizing the relational universe leads the group with flying phobia to engage in two main types of relationship dynamic.

The first of these dynamics is reflected in the bipolar semantics of "Distancing oneself - Drawing closer", in relation to which participants with phobia tended to position themselves near the former pole, referring predominantly in their self-characterizations to the act of "closing up" (retreat- 
ing into oneself, totally shut off, being closed, keeping one's problems to oneself, preferring to keep a low profile..) and "isolating oneself" (managing by oneself, keeping oneself to oneself, preferring to cut themselves off, leading a solitary existence). The fact that these constructs are those most frequently mentioned by subjects with fear of flying suggests that they are typical of the self-construals of this group.

The second dynamic is expressed by the bipolar semantics of "Breaking free-Depending on', in relation to which the subjects with phobia more frequently position themselves at the "Dependence" pole, frequently drawing on the construct "getting help" (asking for help, getting help, not hesitating to ask for help.. ) as their preferred mode of establishing relationships with other people. This second approach to relationships is more characteristic of how participants construe their close relationships or their positioning within their families, while the first approach reflects their perception of a generalized other as dangerous and unpredictable.

\section{DISCUSSION}

Construing the outside world as unsafe also underlies other aspects of the positioning of the self. For example, in line with the grids proposed by Ugazio et al. [27], subjects affected by phobia refer both to the dimension "BraveFearful" - tending to position themselves at the latter pole by describing themselves as "shy" - and to the dimension "Strong-Weak", with frequent use of the construct "emotional" to express a self-perception of fragility. Finally, the emotions mentioned most frequently by the participants with fear of flying included - as well as general references to "bad mood" - dimensions associated with a phobic organization of personality: specifically "fear" and "anxiety" were amongst the core constructs used to define the self.

In contrast, the control group participants tended to use words such as "brave" (is not afraid, does not get frightened, does not hang back..) that reflect the emotional dimension of the semantics of freedom ("Fear-Courage") and definition of self ("Brave-Fearful"). The subjects in the control group tended to position themselves at the opposite pole to the group with flying phobia. However, the fact that this bipolar semantics featured in the vocabulary of both groups in our study, does not confirm the hypothesis that it is peculiar to a phobic organization of meaning within particular families. Rather, it implies that this dimension of meaning is deeply rooted in the broader cultural and discursive context in which all our participants are immersed.

\section{CONCLUSIONS}

A complex picture of the FOF patient emerges from this study, confirming the results of our own earlier work [24]. Specifically, attachment style appears to be a necessary but insufficient condition for predicting fear of flying. A greater role in the disorder is played by the organization of patients' personality, as argued by Guidano [13] and Ugazio [14]. Conflicting tensions between a need for protection and a need for freedom characterize the meanings system of aviophobics, causing suffering and fear. Avoidant or ambivalent attachment styles lead these individuals to require independence and freedom and flying can be a metaphor for the need to escape from oppressive relationships $[14,28]$. In contrast, fear of flying sufferers tend to describe themselves as "anxious", "weak" and "frightened" by a world perceived as dangerous and uncertain; flying in this case represents the risk of forgoing key relationships guaranteeing care and protection. Difficulty in reconciling these two contrasting but salient needs, contributes to the development of symptoms. Panic attacks and the fear of imminent death and catastrophe, drive the patient to prefer close relationships [14]. Conversely, phobia sufferers' feelings of depersonalization, suffocation and oppression, may mask an equally important need to define themselves as effective, autonomous, free and independent.

The limitations of this study include the small number of participants and the restricted nature of the analysis carried out on the self-characterizations, both factors which prevent us from generalizing from the results.

Nonetheless, our findings suggest that is crucial to supplement diagnoses based on symptoms and their degree of severity or unpleasantness, with diagnostic assessments that consider the personal constructs and system of meanings of the patient $[13,14,17]$. If we view the human being as a biopsycho-social entity, even physical and psychological symptoms may be interpreted as indicators of the patient's construal system [17] and his/her positioning in the learning context, factors which may either contribute to or protect against the development of a pathology.

\section{CONFLICT OF INTEREST}

The authors confirm that this article content has no conflicts of interest.

\section{ACKNOWLEDGEMENT}

None declared.

\section{REFERENCES}

[1] Hirsch JA. Virtual reality exposure therapy and hypnosis for flying phobia in a treatment-resistant patient: a case report. Am J Clin Hypn 2012; 55(2): 168-73.

[2] Wallach H, Bar-Zvi M. Virtual-reality-assisted treatment of flight phobia. Isr J Psychiatry Relat Sci 2007; 44: 29-32.

[3] Agras S, Sylvester D, Oliveau D. The epidemiology of common fears and phobias. Compr Psychiatry 1969; 10: 151-6.

[4] Klein RA. Virtual reality exposure therapy in the treatment of fear of flying. J Contemp Psychother 2000; 30: 195-20.

[5] McNally RJ, Loura CE. Fear of flying in agoraphobia and simple phobia: distinguishing features. J Anxiety Disord 1992; 6: 319-47.

[6] Skolnick B, Schare ML, Wyatt KP, Tillman MA. Aviophobia assessment: validating the flight anxiety situations questionnaire as a clinical identification measure. J Anxiety Disord 2012; 26(8): 77984.

[7] American Psychiatric Association (APA). Diagnostic and statistical manual of mental disorders. $4^{\text {th }}$ ed. Washington, DC: APA 2000.

[8] American Psychiatric Association (APA). Practice guidelines for the treatment of psychiatric disorders. Washington, DC: APA 2004.

[9] Laker M. Specific phobia: flight. Activ Nerv Super 2012; 54(3-4): 108-17.

[10] Neimeyer RA, Mahoney MJ, Eds. Constructivism and psychotherapy. Washington: APA 1995.

[11] Raskin JD, Bridges SK, Eds. Studies in meaning: Exploring constructivist psychology. New York: University Press 2002.

[12] Guidano V. The self in process: toward a post-rationalist cognitive therapy. New York: Guilford Press 1991.

[13] Guidano V. Complexity of the self. New York: Guilford Press 1987. 
[14] Ugazio V. Semantic polarities and psychopathologies in the family: permitted and forbidden stories. London: Springer 2013.

[15] Palazzoli MS, Boscolo L, Cecchin GF, Prata G. Paradox and Counter Paradox. New York: Jason Aronson 1978.

[16] Watzlawick P, Beavin JH, Jackson DD. Some tentative axioms of communication: in pragmatics of human communication: a study of interactional patterns, pathologies, and paradoxes. New York, NY: W. W. Norton \& Company 1967; pp. 48-71.

[17] Kelly GA. The psychology of personal constructs. New York: Norton 1955.

[18] Procter HG. Family construct psychology: an approach to understanding and treating families. In: Walrond-Skinner S, Ed. Development in family therapy. London: Routledge 1981.

[19] Procter HG. The Family Construct System. In: Kalekin-Fishman D, Walker B, Eds. the structure of group realities: culture and society in the light of personal construct theory. Malabar, Florida: Krieger 1996.

[20] Procter HG. Family Therapy. In: Fransella F, Ed. Essential pracitioners' handbook of personal construct psychology. London: Sage 2005.

[21] Procter HG. Developments in personal and relational construct psychology: qualitative grids and the levels of interpersonal construing. In: Raskin JD, Bridges SK, Kahn JS, Eds. Studies in meaning 5: dialogues and diatribes in constructivist psychology. New York: Pace University Press 2012.

[22] Harré R, Langenhove LV. Positioning theory: moral context of intentional action. Oxford: Blackwell Publishers 1999.

[23] Cronen VE, Johnson KM, Lannaman KM. Paradoxes, double binds and reflex ive loops: an alternative theoretical perspective. Fam Process 1982; 21: 91-112.

[24] Veronese G, Romaioli D, Castiglioni M. Attachment styles and construction of self in a clinical group of aerophobic: a pilot study. Psychol Stud 2012; 57(3): 303-9.

[25] Castiglioni M, Faccio E, Veronese G, Bell R. The Semantics of power: a comparison between obesity, anorexia and bulimia. J Constr Psychol 2013; 26(1): 62-76.

[26] Veronese G, Ruggiero GM, SassaroliS, Castiglioni M. Interpersonal and individual factors in the grandiose fantasies and threats to self-esteem of a non-clinical Sample. Open Psychol J 2011; 4: 1-5.
[27] Ugazio V, Negri A, Fellin L, Di Pasquale R. The Family Semantics Grid (FSG): the narrated polarities. A Manual for the Semantic Analysis of Therapeutic Conversations and Self Narratives. TPM Test Psychomatr Methodol Appl Psychol. 2009; 16(4): 165-92.

[28] Castiglioni M, Veronese G, Pepe A, Villegas-Besora M. The semantics of freedom in agoraphobic patients: an empirical study. $\mathrm{J}$ Constr Psychol 2013 [Epub ahead of print].

[29] Bowlby J. Attachment and loss. Separation. New York: Basic Books 1973; vol. 2.

[30] Bowlby J. Attachment and loss, 3, loss, sadness and depression. London: Hogart Press 1980.

[31] Bowlby J. Attachment \& Loss: vol. I. Attachment, $2^{\text {nd }}$ ed. New York: Basic Books 1982.

[32] Hazan C, Shaver P. Romantic love conceptualized as an attachment process. J Pers Soc Psychol 1987; 52(3): 511-24.

[33] Feeney JA, Noller P, Callan VJ. Attachment style, communication and satisfaction in the early years of marriage. In: Bartholomew K, Perlman D, Eds. Advances in personal relationships: adult attachment relationships. London: Jessica Kingsley 1994; vol.5: pp. 269-308.

[34] Fossati A, Feeney JA, Donati D, et al. On the dimensionality of the attachment style questionnaire in Italian clinical and nonclinical participants. J Soc Pers Relat 2003; 20(1): 55-79.

[35] Bartholomew K, Horowitz LM. Attachment styles among young adults: A test of a four category model. J Pers Soc Psychol 1991; 61: 226-44

[36] Feeney JA, Noller P, Hanrahan M. Assessing adult attachment. In Sperling MB, Berman WH, Eds. Attachment in adults: clinical and developmental perspectives. New York, Guilford Press 1994, pp.128-52.

[37] Kelly GA. The psychology of personal constructs. 2 vols. London: Routledge 1991.

[38] Androutsopoulou A. The self-characterization as a narrative tool: applications in therapy with individuals and families. Fam Process 2001; 40(1): 79-94.

[39] Krippendorf K. Content analysis an introduction to its methodology. $2^{\text {nd }}$ ed. Thousand Oaks: Sage Publication 2004.

Received: September 03, 2013

(C) Veronese et al.; Licensee Bentham Open.

This is an open access article licensed under the terms of the Creative Commons Attribution Non-Commercial License (http://creativecommons.org/licenses/ by-nc/3.0/) which permits unrestricted, non-commercial use, distribution and reproduction in any medium, provided the work is properly cited. 